\title{
What is rate-limiting during sustained synaptic activity: vesicle supply or the availability of release sites
}

\author{
Erwin Neher* \\ Department of Membrane Biophysics, Max Planck Institute for Biophysical Chemistry, Goettingen, Germany
}

\section{Edited by:}

Robert Renden, Union Chimique Belge

Pharma SA, Belgium

\section{Reviewed by:}

Robert Renden, Union Chimique Belge

Pharma SA, Belgium

Michael Alan Cousin, University of

Edinburgh, UK

Ruth Heidelberger, University of Texas

Medical School at Houston, USA

*Correspondence:

Erwin Neher, Department of

Membrane Biophysics, Max Planck

Institute for Biophysical Chemistry,

Am Faßberg 11, 37077 Goettingen,

Germany.

e-mail: eneher@gwdg.de
For some types of synapses the availability of release-ready vesicles is a limiting factor during ongoing activity. Synaptic strength in this case is determined both by the recruitment of such vesicles and the probability of their release during an action potential. Here it is argued that not the availability of vesicles is the limiting factor for recruitment, but rather the availability of specific sites to which vesicles can dock.

Keywords: calyx of Held, endocytosis, exocytosis, neurotransmitter release, synapse
Many synapses in the central nervous system transmit tonically at high rates, particularly those mediating signals from sensory inputs (Rancz et al., 2007; Kopp-Scheinpflug et al., 2008; Lorteije et al., 2009). For instance, fibers of the auditory nerve fire up to $100 \mathrm{~Hz}$, even in complete silence (Taberner and Liberman, 2005; Hermann et al., 2007) and some auditory synapses are capable of reliably transmitting at such high rates (Wu and Kelly, 1993; Taschenberger and von Gersdorff, 2000). A number of studies have addressed the question on how nerve terminals manage to maintain high release rates, given that there are a limited number of vesicles in a synaptic bouton. Vesicles have to be recycled and loaded with neurotransmitter before being ready for reuse. Almost exclusively vesicles and the vesicle cycle have been at the center of attention in previous studies; see (Fernandez-Alfonso and Ryan, 2004; Südhof, 2004; Rizzoli and Betz, 2005) for review. The issue has fuelled debates about short-cuts in the cycle, such as kiss-and-run exo/endocytosis (Stevens and Williams, 2000; Zhang et al., 2009) and the role of reserve pools (Kuromi and Kidokoro, 1998; Murthy and Stevens, 1999; Ikeda and Bekkers, 2009). There is, however, yet another possible bottleneck in the cycle, which is the availability of receptive release sites, to which vesicles can dock. Although a fixed number of release sites has been a firm concept of synaptic research since Katz (1969), representing the basis for all of binomical statistical analysis (Clements and Silver, 2000; Scheuss and Neher, 2001), little attention has been paid so far to the possibility that intact release sites may be the rate-limiting resource during high sustained demand; but see Dittman and Regehr (1996), Kawasaki et al. (2000), Pan and Zucker (2009). Here, I will assume that a release site (= vesicle docking site) can exist in three different states: (i) empty and accessible for a vesicle (ii) occupied, ready for its vesicle to exocytose (iii) empty and refractory (not accessible for a vesicle shortly after a fusion event); see also Figure 1. I will argue that, indeed, the demand on availability of release sites may be much more stringent than that on vesicle supply. Also, I will discuss some recent results, which invoke endocytic molecules in controlling a rapid step in the cycle, probably mediating clearance of release sites from vesicular components, with which they interacted before and during exocytosis.

\section{EVIDENCE FOR A FIXED NUMBER OF RELEASE-SITES}

The statistics of quantal release have provided early evidence for a limited number of release sites (see Clements and Silver, 2000 for review). Basically, this notion results from the finding that fluctuations in the number of quanta released per pre-synaptic stimulus become very small at very high release probability (e.g. under high calcium concentration). This is exactly what one expects for a fixed number $N$ of release- (or vesicle docking-sites) and a release probability $p_{r}$ near one. Most stimuli will then release nearly $N$ vesicles with little trial to trial variability. Physiologists, therefore, have been quite confident, that a given synaptic connection is equipped with a welldefined number of release-sites, which are used repetitively upon stimulation. Quite a number of studies went even further demonstrating that the number $N$ derived from release statistics agrees well with the morphologically determined number of active zones (AZ) at a given synaptic junction (Korn et al., 1981) or with the number of boutons (Silver et al., 2003). Since there can be several vesicles ( $\approx 3-6)$ morphologically docked at an AZ, it was postulated that there must be a so-called "single vesicle release constraint" in the sense that once one vesicle has been released at a given AZ, no further release events are possible at this $\mathrm{AZ}$ within some refractory period (Stevens and Wang, 1995). However, more recently several exceptions to that rule have been found (Wadiche and Jahr, 2001; Oertner et al., 2002). Also, it has been shown that postsynaptic receptor saturation may bias the statistical estimate of $N$, such that it artifactually seems to agree with the number of active zones (Meyer et al., 2001). At the calyx of Held nerve terminal (on which most of the quantitative arguments, to be 


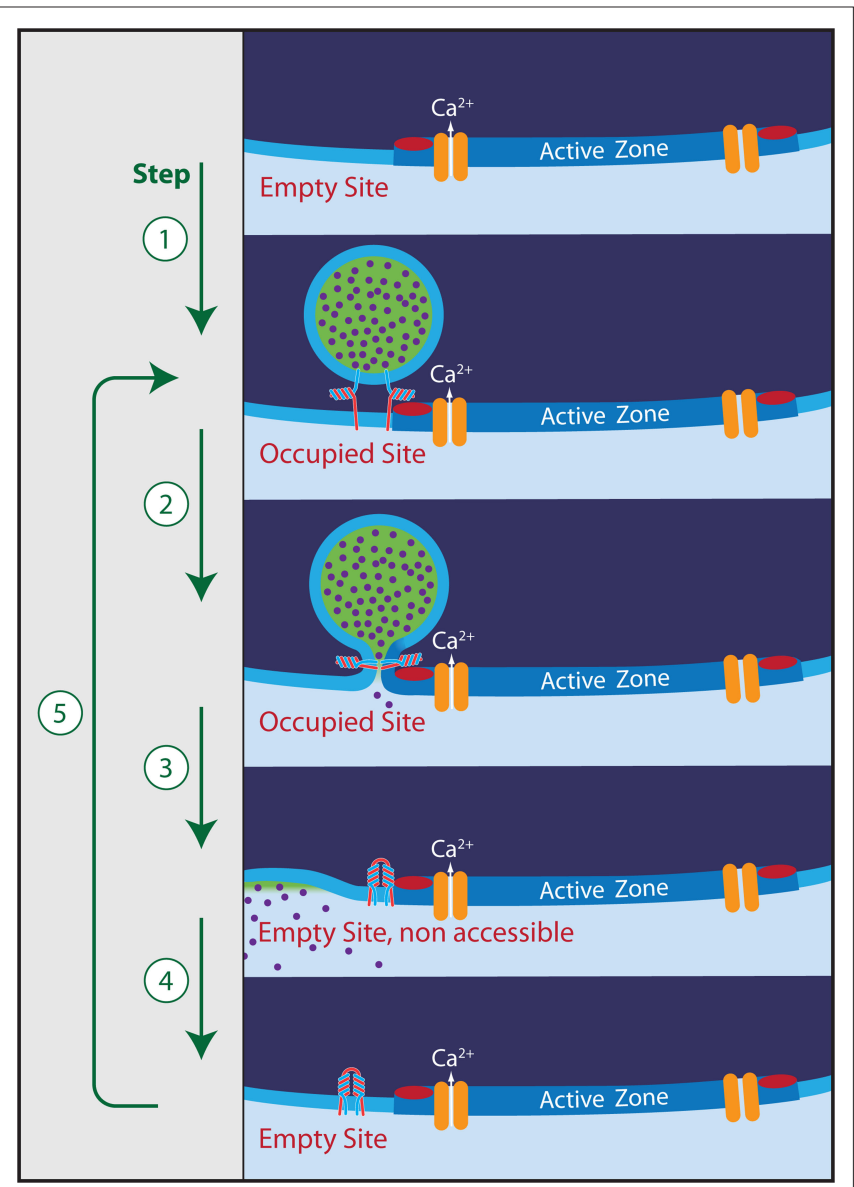

FIGURE 1 |The release cycle. Five steps can be identified: (1) Docking of a vesicle to an empty release site (red bar). Mean residence time of a vesicle is at least $40 \mathrm{~s}$ in the absence of stimulation. (2) $\mathrm{Ca}^{2+}$-triggered exocytosis. (3) Removal of the vesicle by full collapse fusion or by kiss-and-run. Some vesicular components may still be bound to the release site, leaving it non-accessible for the docking of a new vesicle. (4) Clearance of the release site by dissociation of remaining interaction partners (must happen within $200 \mathrm{~ms}$ during high-frequency stimulation). (5) Docking of a new vesicle (equivalent to step 1). The symbol for the entity blocking the release site in the non-accessible state was chosen to resemble a cis-SNARE complex. Such complexes, in association with Rim, Munc-13, synaptotagmin, and possibly Ca-channels may, indeed, be the postulated blockers. However, this assignment and the relationship of such a complex to endocytosis is clearly a matter of speculation in the framework of this electrophysiology-based perspective.

discussed below, are based) a three-dimensional reconstruction of electron micrographs has identified about 500 active zones (Satzler et al., 2002). At least 1500 vesicles can be released at this synapse within a few milliseconds, without evidence for a single vesicle release constraint (Sakaba and Neher, 2001). For the following discussion I will, therefore, assume that there are three equivalent and independent release sites per active zone.

Another piece of evidence for a fixed number of release sites results from kinetic studies. If there were no limiting factors for vesicle docking, the number of docked and primed vesicles at steady-state, in the absence of stimulation, should be the result of a dynamic equilibrium between a docking/priming reaction and its reverse. "Undocking/ unpriming" of vesicles has, indeed, been observed in TIRF studies on retinal bipolar cells (Zenisek et al., 2000) and its functional consequences have been studied in neuroendocrine cells (Dinkelacker et al., 2000). Also, the priming rate in adrenal chromaffin cells is strongly dependent on the intracellular $\mathrm{Ca}^{2+}$ concentration $\left(\mathrm{Ca}^{2+}\right)$. Large changes in the number of release-ready secretory granules when changing $\left(\mathrm{Ca}^{2+}\right)$ were observed in agreement with the expectation of a dynamic equilibrium (Voets, 2000). In contrast, no such increases in the size of the readily releasable pool of vesicles (RRP) could be detected in the calyx of Held terminal, when increasing $\left(\mathrm{Ca}^{2+}\right)$ (Sakaba and Neher, 2001; Hori and Takahashi, 2009) although the priming rate of vesicles in this preparation is highly dependent on $\left(\mathrm{Ca}^{2+}\right)$ (Hosoi et al., 2009). It is therefore concluded that during periods of rest the RRP fills up to a level, which is dictated by the number $N$ of available sites. Given that no changes could be documented and assuming a change $>20 \%$ might have been recognized, one may conclude that under normal resting conditions at least $80 \%$ of the sites are occupied. Together with the experimental finding that the basal priming rate (at zero $\mathrm{Ca}^{2+}$ ) is about 0.1 pools/s, a simple model of reversible priming would predict that the "unpriming rate" is smaller than 0.025 , or else that the mean residence time of a vesicle at a given site is at least about $40 \mathrm{~s}$ in the absence of stimulation. This view is in line with estimates for vesicle undocking times (2 min) in hippocampal neurons, using styryl dyes (Murthy and Stevens, 1999).

\section{SOME NUMBERS FROM THE CALYX OF HELD}

The calyx of Held (Held, 1893) is a large glutamatergic nerve terminal in the auditory pathway. The synapse, located in the medial nucleus of the trapezoid body, is amenable to simultaneous dual voltage clamp of the pre- and postsynaptic compartments. This allows one to perform a detailed biophysical analysis of synaptic transmission (Forsythe, 1994; Borst et al., 1995). Also a 3-D morphometric EM-reconstruction is available (Satzler et al., 2002) such that many aspects of this synapse are quantitatively well defined (Meinrenken et al., 2003; Neher and Sakaba, 2008). Fibers emanating from the globular bushy cells in the ventral cochlear nucleus, which form the calyx, fire at rates between 1 and $200 \mathrm{~Hz}$ in complete silence and can reach frequencies of $500 \mathrm{~Hz}$ during tone bursts (Kopp-Scheinpflug et al., 2008; Lorteije et al., 2009). In acute slices, using $100-\mathrm{Hz}$ stimulation, the synapse of juvenile animals (postnatal day 12-14) has been shown to support quantal contents of about 40-50 vesicles per action potential for periods up to half a second (Taschenberger et al., 2005). The number of active zones is about 500-700 and the number of release sites - or else the RRP-size after periods of rest - is 1500-1800 (see Neher and Sakaba, 2008 for review). Thus, one can conclude that during the first second of $100-\mathrm{Hz}$ stimulation each release site is used about three times per second $(100 \mathrm{~Hz} \times 45$ quanta/stim divided by the RRP). A very similar number for site usage can also be calculated from the quantal content of steady-state responses under $500-\mathrm{Hz}$ stimulation of mature calyces at $37^{\circ} \mathrm{C}$ ( see Table 1 ). Remarkably, the same quantal content was found for recordings in $2 \mathrm{mM}$ external $\left(\mathrm{Ca}^{2+}\right)$ and in $1.2 \mathrm{mM}$ external $\left(\mathrm{Ca}^{2+}\right)$ (Lorteije et al., 2009), although release probability under the latter condition is quite low. The total number of vesicles in a calyx terminal was estimated between 77000 (Satzler et al., 2002) and 188000 (de Lange et al., 2003). Thus, each vesicle is used every 13 or $30 \mathrm{~s}$ depending on which estimate is used and provided that vesicle pools intermix during such strong stimulation. 
Table 1 | Kinetic and morphometric parameters ${ }^{a}$ for the calyx of Held nerve terminal.

\begin{tabular}{|c|c|c|}
\hline No. of active zones & 500 & Satzler et al. (2002) \\
\hline Total no. of vesicles & $77000-180000$ & Satzler et al. (2002), de Lange et al. (2003) \\
\hline Recycling pool, no. of vesicles & $20000-40000$ & de Lange et al. (2003), Yamashita et al. (2005) \\
\hline No. of recycling vesicles per site & 20 & See above \\
\hline No. of slowly releasing vesicles & 1500 & Sakaba and Neher (2001) \\
\hline \multirow[t]{3}{*}{ Max. usage of specific release sites } & $3 / s$ & Docking-release cycles at $100 \mathrm{~Hz}$ stimulation; p12-14; room temperature ${ }^{\mathrm{b}}$ \\
\hline & $3.5 / \mathrm{s}$ & At $500 \mathrm{~Hz}$; adult; $37^{\circ} \mathrm{C}^{\circ}$ \\
\hline & $1.5 / \mathrm{s}$ & At $60 \mathrm{~Hz}$; adult gerbil; $37^{\circ} \mathrm{C}^{d}$ \\
\hline \multirow[t]{2}{*}{ Max. time for reuse of a given vesicle } & $13-30 s$ & At $100-\mathrm{Hz}$ stimulation, if all vesicles are recycling \\
\hline & $2.5-5 \mathrm{~s}$ & ... If only the "recycling pool" is active \\
\hline
\end{tabular}

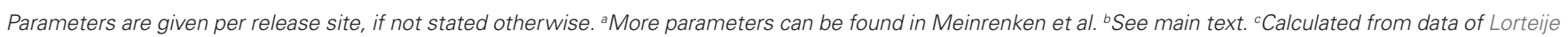

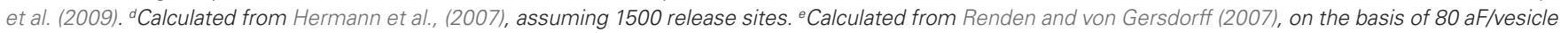
and three sites per active zone.

In case only the "recycling pool" participates, estimated to be 20000 vesicles (de Lange et al., 2003) to 40.000 vesicles (Yamashita et al., 2005), each of these vesicles would still be used only once every 2.5-5 s (see Table 1 for a summary of parameters).

\section{DEMANDS ON VESICLES AND RELEASE SITES}

The comparison of these numbers regarding usage of release sites with those of vesicle usage shows that demands on sites are much more stringent than those on vesicles.

One may ask: Are these numbers comparable? After all, a vesicle has to be endocytosed after sorting of vesicular and plasma membrane components. It has to be uncoated and filled with transmitter before becoming available again for docking and priming. Compared to that, refurbishing a release site seems to be trivial. However, one must keep in mind that before exocytosis the vesicle is stably attached to the release site (Figure 1) with a residence time of $40 \mathrm{~s}$ or longer (see above). This interaction may occur between vesicular components (e.g. synaptobrevin, synaptotagmin, rab3) and those at the plasma membrane (SNARES, Munc13, Ca-channels, Rim). The mere process of exocytosis not necessarily weakens the interaction. However, the dissociation must happen in less than $200 \mathrm{~ms}$ once exocytosis has occurred (assuming that about half of the cycle time of release sites, $330 \mathrm{~ms}$, is spent on docking/priming and the other half on this process). This involves a weakening of the interaction by a factor of 200 (=40/0.200). The "catalytic mechanism", which brings about this weakening, or else the process, which mediates the rapid "run" (in kiss and run) still have to be found. In any case, the demand on the release-site cycle (see Figure 1) may not be trivial at all.

\section{TWO TYPES OF RELEASE EVENTS AT THE CALYX OF HELD}

The discussion of neurotransmitter release at the calyx of Held so far dealt only with a fraction of its release capacity. Upon prolonged depolarization (under voltage clamp) an additional 1500 vesicle can be released slowly. These vesicles contribute only little to actionpotential-induced release (Sakaba, 2006), but may play a role in asynchronous release during high-frequency stimulation. A striking property of this vesicle pool is that it recovers very rapidly during short rest periods, even faster than the rapidly releasing vesicles do at the highest possible $\left(\mathrm{Ca}^{2+}\right)$ (Sakaba and Neher, 2001). Unlike the rapidly releasing vesicles, the recovery of which is strongly retarded by blockers of calmodulin, their recovery is robust and not influenced by any of the modulators tested - except for depletion of ATP and interfering with the cytoskeleton (Sakaba and Neher, 2003b). A most interesting question is why this vesicle pool is faster in its recovery. This obviously is linked to a second question why these vesicles release more slowly than the other ones. Two answers have been provided to this latter question. Caged $\mathrm{Ca}^{2+}$ measurements (Wolfel et al., 2007) demonstrated that there is intrinsic heterogeneity with respect to the $\mathrm{Ca}^{2+}$ sensitivity of release-ready vesicles in the calyx of Held. This finding was proposed to be the basis for the kinetic heterogeneity in depolarization-induced release. However, another caged $\mathrm{Ca}^{2+}$ study (Wadel et al., 2007), which measured the $\mathrm{Ca}^{2+}$ sensitivity of vesicles remaining after depletion of the rapidly releasing vesicle pool by a short depolarization, found that the $\mathrm{Ca}^{2+}$ sensitivity of these vesicles (which should be slow ones) was only slightly reduced. This suggested that the main reason why slow vesicles do not respond so well to action potentials is their location relative to $\mathrm{Ca}^{2+}$ channels: If they were docked somewhat more remote from $\mathrm{Ca}^{2+}$ channels, they would not sense the localized $\mathrm{Ca}^{2+}$ microdomains, which build up and decay rapidly when $\mathrm{Ca}^{2+}$ channels open transiently during action potentials. Together with the concept of specific release sites at active zones, where a high density of $\mathrm{Ca}^{2+}$ channels prevails, this view also provides a reasonable explanation for the first question: Slowly releasing vesicles recover more rapidly, because they need not "find" a specific release site. Similar to the "newcomers", observed in TIRF microscopy (Zenisek et al., 2000), they can dock and develop their release apparatus anywhere near the active zone (and, maybe, elsewhere). Only vesicles, destined to be rapidly released from specific sites (near $\mathrm{Ca}^{2+}$ channels), need to either find such sites and/ or wait until such sites become available. 


\section{SITE-CLEARANCE AND ENDOCYTOSIS}

Several recent studies interfering with the function of "endocytic" proteins have reported inhibitory effects on vesicle exocytosis. Some of these effects develop too rapidly for being explained by a lack of recycled vesicles. The first study, pointing out this problem used the temperature-sensitive fly mutant "shibire" (Kawasaki et al., 2000). Shibire affects the protein dynamin, which facilitates the pinching off of vesicles (Mettlen et al., 2009). Kawasaki et al. observed that flies at non-permissive temperatures exhibited a fatigue phenotype within $20 \mathrm{~ms}$. This is much shorter than the time required for endocytosed vesicles to become re-available for exocytosis, which is typically on the order of $10 \mathrm{~s}$ (Betz and Wu, 1995; Fernandez-Alfonso and Ryan, 2006). Therefore, Kawasaki et al. (2000) concluded that a block of endocytosis alone and the resulting lack of vesicles cannot be the cause for the paralysis. Rather, they postulated that clearance and re-priming of release sites is occluded by accumulation of endocytic intermediates at such sites. A number of other studies have interfered with various proteins, believed to be part of the endocytic machinery, and demonstrated very rapidly developing effects on exocytosis (Shupliakov et al., 1997; Chen et al., 2003; Ferguson et al., 2007). A very sensitive phenomenon in this respect is short-term synaptic depression (STD), which is observed in many types of glutamatergic synapses. STD is a reduction in synaptic responses, which typically sets in within the first 2-5 EPSCs, when stimulating at frequencies of 10-100 Hz. Part of this decrease is a reduction in the number of available vesicles. STD reaches a steady-state within some 10-20 stimuli, which reflects a balance between vesicle usage and recruitment of new vesicles. The typical phenotype of the relevant studies on endocytic proteins is an intact initial EPSC, but a deepening of STD and a slow-down of recovery from STD. Since such effects can also be observed early after blocking endocytosis (before the vesicle store is depleted) the limited availability of vesicles for docking and priming is unlikely to be the cause for this depression.

A recent study (Hosoi et al., 2009) observed this same phenotype for six different manipulations involving proteins, which either participate in endocytosis or else have to be sorted before endocytosis. These manipulations were

- infusion of a peptide which interferes with the binding of dynamin to amphiphysin

- external application of dynasore, which blocks the GTPase activity of dynamin

- infusion of a dynamin antibody

- infusion of a peptide disrupting the interaction between AP2 and amphiphysin

- infusion of a peptide from the N-terminal proline-rich domain of synaptobrevin

- infusion of the $\mathrm{C} 2 \mathrm{~B}$ domain of synaptotagmin 2

The authors concluded that "block of endocytosis has a limited retrograde action on exocytosis, delaying recruitment of release-ready vesicles and enhancing short-term depression". They noted that this effect develops rapidly, while endocytosis itself (as measured by a change in membrane capacitance) is a relatively slow process, taking tens of seconds until completion.
It is, therefore, likely that the respective manipulations affect a step in between exo- and endocytosis, which is necessary for the restoration of a release-site. Translocation of synaptic components from sites of exocytosis to the "periactive zone" (Roos and Kelly, 1999) may be a candidate for this step, which may be perturbed by these manipulations or simply slowed by the accumulation of vesicular proteins. It should be stressed that this step, whatever it is molecularly, has important physiological roles, since it determines synaptic strength during second-long episodes of sustained activity (Hosoi et al., 2009) and was shown to be a target for modulation by second messengers, such as $\mathrm{Ca}^{2+}$ and cAMP (Sakaba and Neher, 2003a).

A second limitation on sustained release is set by endocytosis itself (Figure 2). Maximum rates of endocytosis after short, strong stimuli were found to be 10-20 fF/s (Sun et al., 2002; Yamashita et al., 2005; Hosoi et al., 2009). Assuming a value of $80 \mathrm{aF}$ for the capacitance of a single vesicle (Sakaba, 2006) this corresponds to $125-250$ vesicles per second or $0.08-0.17$ vesicles per release site (or about 0.4 vesicles per active zone). This is about 25 times smaller than the maximum rates for reuse of sites and will lead to further slow depression, once the recycling pool of vesicles (20 000-40 000 vesicles, see above) is being used up. At $100-\mathrm{Hz}$ stimulation this is expected to occur after about $6 \mathrm{~s}$. The number of stimuli (600) is similar to that typically used for labeling the recycling pool in hippocampal nerve terminals (Murthy and Stevens, 1999). Also, the rates of endocytosis per release site are similar between the two types of synapses (Sankaranarayanan and Ryan, 2001) and they are of the same order of magnitude as rates of vesicle replenishment after long periods of intense stimulations (Wesseling and Lo, 2002). In this sense, the properties of the juvenile calyx of Held, discussed here, are very much in line with those at other glutamatergic synapses (see also a comparison of different synapses by Fernandez-Alfonso and Ryan (2006), but note that numbers are given per active zone, not per release site. Conversion: three sites per active zone). If such slow rates of endocytosis were the physiologically relevant ones, one would expect that the synapse undergoes deep depression after intense stimulation for more than a few seconds. The recycling pool of 20000 vesicles would be expected to be refilled only after a few minutes. In contrast, Hermann et al. (2007), stimulating calyces of the gerbil at $60 \mathrm{~Hz}$, found that after an initial fast phase of depression release remained constant for several seconds at a quantal content of approximately 50 quanta (assuming an mEPSC of $50 \mathrm{pA}$ ), which further decayed within a minute only by about $30 \%$ and remained constant thereafter. Thus, this synapse can sustain much higher rates of vesicle turnover than expected on the basis of measured membrane retrieval rates ( 1.5 quanta per sec and site, assuming 1500 sites). Several findings may explain the discrepancy: (i) Faster rates of membrane retrieval have been observed following excessive stimulation (Richards et al., 2000; Sun et al., 2002; de Lange et al., 2003). (ii) Endocytic capacity increases with age and temperature (Renden and von Gersdorff, 2007), see Table 1; (iii) species differences; (iv) endocytic capacity is partially lost during prolonged whole-cell recording (Smith and Neher, 1997; Renden and von Gersdorff, 2007); (v) vesicles of the reserve pool may be mobilized (Ikeda and Bekkers, 2009). 


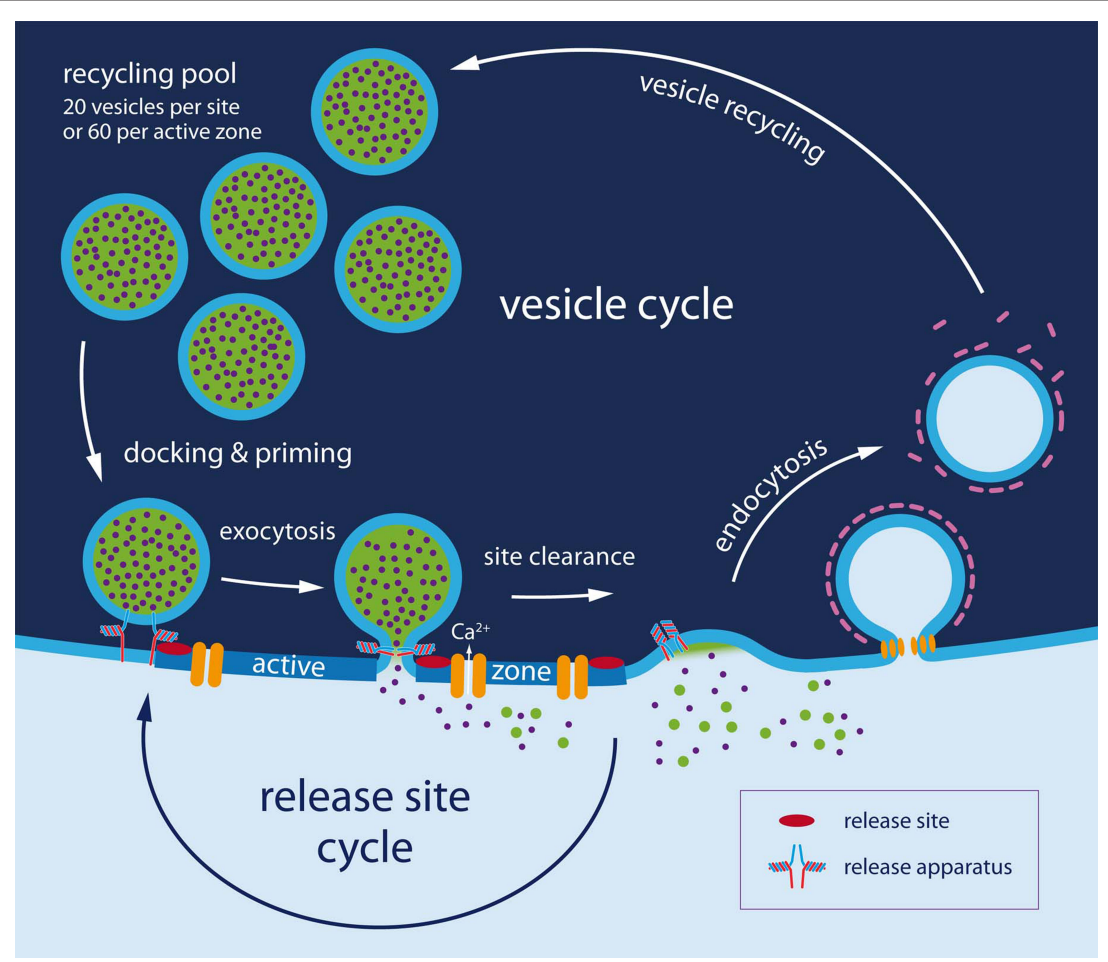

FIGURE 2 |The dual cycle. At least two entities need recycling: The release site (shown in detail in Figure 1) and vesicles. Regarding vesicles three additional steps must be considered. (1) Endocytosis, which takes several seconds in patch clamped calyces and hippocampal cultures. (2) Vesicle recycling: $10 \mathrm{~s}$ of seconds
(3) Vesicle docking and priming. It is proposed (Neher and Sakaba, 2008; Hosoi et al., 2009) that vesicle docking and priming actually occurs very rapidly (within 100-200 ms) once a release site has been cleared and that site clearing is slow (200 ms to $10 \mathrm{~s}$ ), being modulated by $\left(\mathrm{Ca}^{2+}\right)$ and other signaling pathways.
Taken together these effects may elevate membrane retrieval to a level close to that of maximum rates of sustained exocytosis. If so, reuse of vesicles, which happens on the seconds to minutes time scale, is not likely to be limiting in the normal operation of a synapse, given that there is a large reserve of vesicles and provided that there is the more stringent and activity-dependent limitation for rapid reuse of release sites discussed here.

\section{CONCLUSION}

Scarcity of release-ready vesicles during sustained activity has been an issue of synaptic research since the early studies by Katz et al. on the neuromuscular junction. It is well established that in many types of synapses the level of neurotransmitter release during ongoing activity reflects a balance of vesicle supply and vesicle consumption by exocytosis. Here, it is argued that recycling of vesicles may actually not be the rate-limiting step during physiological activity patterns. Rather the availability of specific sites, to which vesicles can dock, might be the major bottleneck. The main arguments are

\section{REFERENCES}

Betz, W. J., and Wu, L. G. (1995). Synaptic transmission. Kinetics of synaptic-vesicle recycling. Curr. Biol. 5, 1098-1101.

Borst, J.G. G., Helmchen, F., and Sakmann, B. (1995). Pre- and postsynaptic whole-cell recordings in the medial nucleus of the trapezoid body of the rat. J. Physiol. 489, 825-840.

Chen, Y., Deng, L., Maeno-Hikichi, Y., Lai, M., Chang, S., Chen, G., and Zhang, J. F. (2003). Formation of an endophilin- $\mathrm{Ca}^{2+}$ channel complex is critical for clathrin-mediated synaptic vesicle endocytosis. Cell 115, 37-48.

- requirements on such sites are more stringent than those on vesicles

- strong interactions between vesicular components and the active zone must be broken after exocytosis

- refilling of the sites is perturbed by manipulations affecting endocytosis and this effect sets in faster than the time required for reuse of vesicles

- vesicle docking and priming can be very fast, in case vesicles do not target special sites on the active zone.

Unfortunately, all of these points are conjectures, based on indirect arguments or else on findings, which individually may have alternative interpretations. Together, however, they strongly suggest that the dynamics of release sites should be considered as a limiting and modulatory element in synaptic transmission.

\section{ACKNOWLEDGMENT}

I would like to thank T. Sakaba and H. Taschenberger for helpful suggestions on the manuscript.

Clements, J. D., and Silver, R. A. (2000). Unveiling synaptic plasticity: A new graphical and analytical approach. TINS 23, 105-113.

de Lange, R. P., de Roos, A. D., and Borst, J. G. (2003). Two modes of vesicle recycling in the rat calyx of Held. J. Neurosci. 23, 10164-10173.
Dinkelacker, V., Voets, T., Neher, E., and Moser, T. (2000). The readily releasable pool of vesicles in chromaffin cells is replenished in a temperature-dependent manner and transiently overfills at $37^{\circ} \mathrm{C}$. J. Neurosci. 20, 8377-8383.

Dittman, J. S., and Regehr, W. G. (1996). Contributions of calcium-dependent 
and calcium-independent mechanisms to presynaptic inhibition at a cerebellar synapse. J. Neurosci. 16, 1623-1633.

Ferguson, S. M., Brasnjo, G., Hayashi, M., Wolfel, M., Collesi, C., Giovedi, S., Raimondi, A., Gong, L. W., Ariel, P., Paradise, S., O'toole, E., Flavell, R., Cremona, O., Miesenböck, G., Ryan, T. A., and De Camilli, P. (2007). A selective activity-dependent requirement for dynamin 1 in synaptic vesicle endocytosis. Science 316, 570-574.

Fernandez-Alfonso, T., and Ryan, T. A. (2004). The kinetics of synaptic vesicle pool depletion at CNS synaptic terminals. Neuron 41, 943-953.

Fernandez-Alfonso, T., and Ryan, T. A. (2006). The efficiency of the synaptic vesicle cycle at central nervous system synapses. Trends Cell Biol. 16, 413-420.

Forsythe, I. D. (1994). Direct patch recording from identified presynapticterminals mediating glutamatergicEPSCsin the rat CNS, in vitro. J. Physiol. 479, 381-387.

Held,H.(1893). Diezentrale Gehörleitung. Arch. Anat u Physiol. Anat. Abt 17, 201-248.

Hermann, J., Pecka, M., von Gersdorff, H., Grothe, B., and Klug, A. (2007). Synaptic transmission at the calyx of Held under in vivo like activity levels. J. Neurophysiol. 98, 807-820.

Hori, T., and Takahashi, T. (2009). Mechanisms underlying short-term modulation of transmitter release by presynaptic depolarization. J. Physiol. 587, 2987-3000.

Hosoi, N., Holt, M., and Sakaba, T. (2009). Calcium dependence of exo- and endocytotic coupling at a glutamatergic synapse. Neuron 63, 216-229.

Ikeda,K.,and Bekkers,J.M. (2009).Counting the number of releasable synaptic vesicles in a presynaptic terminal. Proc. Natl. Acad. Sci. U.S.A. 106, 2945-2950.

Katz, B. (1969). The Release of Neural Transmitter Substances (The Sherrington Lectures X). Springfield : Charles C Thomas Publisher.

Kawasaki, F., Hazen, M., and Ordway, R.W. (2000). Fast synaptic fatigue in shibire mutants reveals a rapid requirement for dynamin in synaptic vesicle membrane trafficking. Nat. Neurosci. 3, 859-860.

Kopp-Scheinpflug, C., Tolnai, S., Malmierca, M. S., and Rubsamen, R. (2008). The medial nucleus of the trapezoid body: Comparative physiology. Neuroscience 154, 160-170.

Korn, H., Triller, A., Mallet, A., and Faber, D.S. (1981). Fluctuating responses at a central synapse: $\mathrm{N}$ of binomial fit predicts number of stained presynaptic boutons. Science 213, 898-901.

Kuromi, H., and Kidokoro, Y. (1998). Two distinct pools of synaptic vesicles in single presynaptic boutons in a temperature-sensitive Drosophila mutant, shibire. Neuron 20, 917-925.
Lorteije, J. A., Rusu, S. I., Kushmerick, C. and Borst, J. G. (2009). Reliability and precision of the mouse calyx of Held synapse. J. Neurosci. 29, 13770-13784.

Meinrenken, C. J., Borst, J. G., and Sakmann, B. (2003). Local routes revisited: The space and time dependence of the $\mathrm{Ca}^{2+}$ signal for phasic transmitter release at the rat calyx of Held. J. Physiol. 547, 665-689.

Mettlen, M., Pucadyil, T., Ramachandran, R., and Schmid, S. L. (2009). Dissecting dynamin's role in clathrin-mediated endocytosis. Biochem. Soc. Trans. 37, 1022-1026.

Meyer,A.C.,Neher,E.,andSchneggenburger, R. (2001). Estimation of quantal size and number of functional active zones at the calyx of held synapse by nonstationary EPSC variance analysis. J. Neurosci. 21, 7889-7900.

Murthy, V. N., and Stevens, C. F. (1999). Reversal of synaptic vesicle docking at central synapses. Nat. Neurosci. 2, 503-507.

Neher, E., and Sakaba, T. (2008). Multiple roles of calcium ions in the regulation of neurotransmitter release. Neuron $59,861-872$.

Oertner, T.G., Sabatini, B. L., Nimchinsky, E. A., and Svoboda, K. (2002) Facilitation at single synapses probed with optical quantal analysis. Nat. Neurosci. 5, 657-664.

Pan, B., and Zucker, R. S. (2009). A general model of synaptic transmission and short-term plasticity. Neuron 62 , 539-554.

Rancz, E. A., Ishikawa, T., Duguid, I., Chadderton, P., Mahon, S., and Hausser, M. (2007). High-fidelity transmission of sensory information by single cerebellar mossy fibre boutons. Nature 450, 1245-1248.

Renden, R., and von Gersdorff, H. (2007). Synaptic vesicle endocytosis at a CNS nerve terminal: Faster kinetics at physiological temperatures and increased endocytotic capacity during maturation. J. Neurophysiol. 98, 3349-3359.

Richards, D. A., Guatimosim, C., and Betz, W. J. (2000). Two endocytic recycling routes selectively fill two vesicle pools in frog motor nerve terminals. Neuron 27, 551-559.

Rizzoli, S. O., and Betz, W. J. (2005). Synaptic vesicle pools. Nat. Rev. Neurosci. 6, 57-69.

Roos, J., and Kelly, R. B. (1999). The endocytic machinery in nerve terminals surrounds sites of exocytosis. Curr. Biol. 9, 1411-1414.

Sakaba, T. (2006). Roles of the fast-releasing and the slowly releasing vesicles in synaptic transmission at the calyx of held. J. Neurosci. 26, 5863-5871.

Sakaba, T., and Neher, E. (2001). Calmodulin mediates rapid recruitment of fast-releasing synaptic vesicles at a calyx-type synapse. Neuron 32 , 1119-1131.

Sakaba, T., and Neher, E. (2003a). Direct modulation of synaptic vesicle priming by $\mathrm{GABA}(\mathrm{B})$ receptor activation at a glutamatergic synapse. Nature 424 775-778.

Sakaba, T., and Neher, E. (2003b). Involvement of actin polymerization in vesicle recruitment at the calyx of Held synapse. J. Neurosci. 23, 837-846.

Sankaranarayanan, S., and Ryan, T. A. (2001). Calcium accelerates endocytosis of vSNAREs at hippocampal synapses. Nat. Neurosci. 4, 129-136.

Satzler, K., Sohl, L. F., Bollmann, J.H., Borst, J. G., Frotscher, M., Sakmann, B., and Lubke,J.H. (2002). Three-dimensional reconstruction of a calyx of Held and its postsynaptic principal neuron in the medial nucleus of the trapezoid body. J. Neurosci. 22, 10567-10579.

Scheuss, V., and Neher, E. (2001). Estimating synaptic parameters from mean, variance, and covariance in trains of synaptic responses. Biophys. J. 81, 1970-1989.

Shupliakov, O., Low, P., Grabs, D., Gad, H., Chen, H., David, C., Takei, K., De Camilli, P., and Brodin, L. (1997). Synaptic vesicle endocytosis impaired by disruption of dynamin-SH3 domain interactions. Science 276, 259-263.

Silver, R. A., Lubke, J., Sakmann, B., and Feldmeyer,D. (2003). High-probability uniquantal transmission at excitatory synapses in barrel cortex. Science 302, 1981-1984.

Smith, C., and Neher, E. (1997). Multiple forms of endocytosis in bovine adrenal chromaffin cells. J. Cell Biol. 139, 885-894.

Stevens, C. F., and Wang, Y. (1995). Facilitation and depression at single central synapses. Neuron 14, 795-802.

Stevens, C. F., and Williams, J. H. (2000), "Kiss and run" exocytosis at hippocampal synapses. Proc. Natl. Acad. Sci. U.S.A. 97, 12828-12833.

Südhof, T. C. (2004). The synaptic vesicle cycle. Annu. Rev. Neurosci. 27, 509-547.

Sun, J. Y., Wu, X. S., and Wu, L. G. (2002). Single and multiple vesicle fusion induce different rates of endocytosis at a central synapse. Nature 417, 555-559.

Taberner, A. M., and Liberman, M. C. (2005). Response properties of single auditory nerve fibers in the mouse. $J$. Neurophysiol. 93, 557-569.

Taschenberger, H., Scheuss, V., and Neher, E. (2005). Release kinetics, quantal parameters and their modulation during short-term depression at a developing synapse in the rat CNS. J. Physiol. 568, 513-537.

Taschenberger, H., and von Gersdorff, H. (2000). Fine-tuning an auditory synapse for speed and fidelity:
Developmental changes in presynaptic waveform, EPSC kinetics, and synaptic plasticity. J. Neurosci. 20, 9162-9173.

Voets, T. (2000). Dissection of three $\mathrm{Ca}^{2+}$ dependent steps leading to secretion in chromaffin cells from mouse adrenal slices. Neuron 28, 537-545.

Wadel, K., Neher, E., and Sakaba, T. (2007). The coupling between synaptic vesicles and $\mathrm{Ca}^{2+}$ channels determines fast neurotransmitter release. Neuron 53, 563-575.

Wadiche, J. I., and Jahr, C. E. (2001). Multivesicular release at climbing fiber-Purkinje cell synapses. Neuron 32, 301-313.

Wesseling, J. F., and Lo, D. C. (2002). Limit on the role of activity in controlling the release-ready supply of synaptic vesicles. J. Neurosci. 22, 9708-9720.

Wolfel, M., Lou, X., and Schneggenburger, R. (2007). A mechanism intrinsic to the vesicle fusion machinery determines fast and slow transmitter release at a large CNS synapse. J. Neurosci. 27 , 3198-3210.

Wu,S.H., and Kelly,J.B. (1993). Response of neurons in the lateral superior olive and medial nucleus of the trapezoid body to repetitive stimulation: Intracellular and extracellular recordings from mouse brain slice. Hear Res. 68, 189-201.

Yamashita, T., Hige, T., and Takahashi, T. (2005). Vesicle endocytosis requires dynamin-dependent GTP hydrolysis at a fast CNS synapse. Science 307, 124-127.

Zenisek, D., Steyer, J. A., and Almers, W. (2000). Transport, capture and exocytosis of single synaptic vesicles at active zones. Nature 406, 849-854.

Zhang, Q., Li, Y., and Tsien, R. W. (2009). The dynamic control of kiss-andrun and vesicular reuse probed with single nanoparticles. Science 323, 1448-1453.

Conflict of Interest Statement: The author declares that the research was conducted in the absence of any commercial or financial relationships that could be construed as a potential conflict of interest.

Received: 15 July 2010; paper pending published: 26 August 2010; accepted: 26 August 2010; published online: 16 September 2010.

Citation: Neher E (2010) What is ratelimiting during sustained synaptic activity: vesicle supply or the availability of release sites. Front. Syn. Neurosci. 2:144 doi:10.3389/fnsyn.2010.00144

Copyright $(02010$ Neher. This is an openaccess article subject to an exclusive license agreement between the authors and the Frontiers Research Foundation, which permits unrestricted use, distribution, and reproduction in any medium, provided the original authors and source are credited. 